\title{
Is organizational skill a will or a way to a successful lifestyle and workstyle?
}

\author{
Mihaela Laura Bratu, ${ }^{1, *}$, and Lucian - Ionel Cioca ${ }^{1}$ \\ ${ }^{1}$ Department of Industrial Engineering and Management, Faculty of Engineering, Lucian Blaga \\ University of Sibiu, 550024 Sibiu, Romania
}

\begin{abstract}
Organizational skill is a transversal competence, which is formed through concrete life experiences. On the labour market, organizations want high-performing employees with developed organizational skills. The approach of training the organizational competence is inductive, starting from personal life, competence formed through voluntary exercise, and continuing by practicing and improving it during school life and at work, through ways offered by academic education and management, but also through organizational skill management. This paper aims to analyse the concept of organizational skill, from the perspective of mental mechanisms involved in its formation, as well as human resource management strategies, applied at the level of university education. Approaching the organizational skill from both perspectives, the competence will lead to a new lifestyle and workstyle oriented towards performance and success. The level of organizational skill of students was analysed, based on a questionnaire to assess organizational competence and a practical test of organization. Following the analysis of the results, it was observed that a small number of young people are very well organized, and their resistance to change is quite high. Finally, the study offers possible school management strategies for training and developing organizational skills, leading to a successful lifestyle and work.
\end{abstract}

\section{Introduction}

According to the dictionary definition, to organize means to place, to arrange the elements of a whole so as to function organically, according to an adequate plan, towards the fulfilment of a purpose [1]. The semantic sphere of the word organization includes: order, discipline, composition [1]. It is observed that the term organization is correlating and receives meaning in relation to the purpose.

There are differences between the concept of organizational skill and order. The order represents a disposition, regular succession with spatial, temporal, logical, moral, aesthetic character [1]. Organizational skill is perceived as a competence, a comprehensive notion, and order is an action that leads to organization. Being orderly is a behaviour that leads over time to the formation of an organizational skill.

\footnotetext{
*Corresponding author: ybratulaura@gmail.com
} 
From the ontogenetic point of view, the first elements that lead to training organizational skills are the play of making order, and sometimes the child's desire for things to be structured. Even if, through the play with the adult, the children collect toys and make order earlier, still, the ability to be organized starts after the age of 5, when the child can orient his activity towards a goal. Around the age of 6 , the child is in the stage of concrete operations, in which he thinks logically and reversible, of the type here and now, and can make deductions. In this period of formation of the organizational competence, the family has a primordial role, the children perfectly imitating the behaviour of the adults from their house. However, children have the ability to adapt their behaviours to the different social situations in which they find themselves. Even if parents at home, either out of a desire to show their children that they love them or out of insufficient development of their own competences, do not develop children's organizational skills, educational institutions should have this competence as a priority.

In the first years of life, the child does not have the intrinsic motivation for order, but by applying methods of exercising organizational skills, both at home and in school, they lead to internalize the organization process and turn it into a voluntary act, with internal motivation. Organizational competence, integrated in the social context, first appears with functional value, helping the child to function in different contexts: I place the plate and cutlery in a certain order, in order to eat more easily; I put the shoes in their place, so as not to get dirty on my socks, etc. The organizational skill thus becomes a condition for his proper functioning.

In the gymnasium cycle, the young person faces a new challenge: he has to learn and reproduce contents from different disciplines. In this new situation, the school environment does not provide support or provides insufficient support for the new competence required: the ability to mental organization of the activities. In families where parents have developed this competence, children have the chance to receive learning support, but it is often encountering the mentality that all children must do their own lessons, parents not understanding that the new competence required by the education system has never been formed directly. On the other hand, at school level there is no subject of study in the curriculum, from the preparatory class to the faculty, that explicitly develops this competence. Sometimes, teachers with open-mindedness prepare, support and help students learn occasionally.

There is a lack of a common strategy at the level of the pre-university and university education system regarding the development of the youth organization competence. In teachers training there is no concept of pedagogy of organization nor the need to train organizational skills.

There are, however, disciplines that logically structure thinking, forming the competence to organize learners indirectly, such as IT disciplines [2]. In conclusion, organization can be a skill that reflects logical, algorithmic thinking.

Finally, young graduates of higher education enter the labour market with insufficient organizational skills, often chaotic and unable to organize a task and complete it. In the absence of a teaching path directed to the organizational skills, in the absence of a pedagogy of the organization, young people take over exclusively the model of parents and teachers they interact with, and organizational skills become a volitional act of the majority and not an essential requirement of a society.

The concept of organizational skill is variously presented in the scientific works. An interesting interpretation is given by Vysotskaya [3], who associates the concept of selforganizing with motivation, goal-oriented activity, as well as with the concepts of selfgovernment, self-regulation and independence. Organizational skills represent the ability of the individual associated with the ability to organize themselves. It manifests itself in the purposefulness of activity, validity of motivation, planning its activities, independence, 
quick decision-making and responsibility for them, assessments criticality of the result of their actions and sense of duty [4].

Success at the university level correlates with organizational skills. Organizational skills, through the two coordinates: time management and ability to set priorities, have an essential contribution to the success achieved by students, especially for online learning [5]. There are also correlations between technical skills acquired during college and those of organization [6]. They can be developed either in the university learning environment or in industrial projects carried out with business partners [7].

For children, students and adults who show Attention-deficit / hyperactivity disorder, organizational competence is severely affected, especially two components: time management, and planning skills [8-12]. Disorganization and inattention are common among students. These symptoms have been associated with poorer time management and absence or delay in classes, meetings, and work [13-15].

Yes, organization is a key competence, of secondary importance at the level of education, without special hours allocated. There is a core of competencies that are formed directly through school subjects, but young people have other developmental needs that, at the moment, are not included in the curriculum, one of the needs being organizational skills. Organizational competence needs social roles to manifest and develop, but often the values of a society do not primarily reflect this orientation. There are organized, logical, rational, and impulsive, chaotic, and spontaneous peoples. In the context of the need for organizational skills, it would be useful to promote an organization pedagogy.

On the labour market, young people transpose their lifestyle into the work style they have, the organizational competence being reflected both at the level of space organization and at the type of work, intellectual or physical. Companies invest annually amounts for onthe-job training, and for the personal development of employees, in order to train them directly observable and measurable skills. What is the impact of these methods on the work style of employees? We wonder if these methods succeed in transforming the work style of the employees, but beyond that, we wonder if they can motivate people for the organization to become a volitional act that can be found even in the personal lifestyle.

Organization is a competence, a personal ability for function organically to achieve a goal. Organizational competence is transferable, manifesting itself in all the social roles that the individual has, both in personal and professional life. A person who is organized will apply this skill at any time and context throughout existence.

What is the psychological mechanism of formation of the organizational skill and why do we need it? The act of organization presupposes the logical, rational, conscious disposition [16], of all the component elements of a whole. At the personal level, the efficient functioning, at maximum capacity, is conditioned by the act of organization. It can be said that regularity represents the outside of things, while order represents their internal structure.

The organizational competence reflects both a volitional act, of self-formation, and a hereditary act, strengthened by the models within the family, but also a result of the modelling by the society. The brain is an organized entity $[17,18]$. The act of organization can be considered a sine-qua-non condition for the functioning of the human body. Anthropology studies the social organization from ancient times [19], so the competence of organization, integrated in the social space [20], is a perpetuum mobile, an indissoluble prerogative of person from the first moments of life of the human species [21].

In the local culture, the idea that "geniuses see in disorder" is perpetuated. While order takes you on a safe, rational path, which has as its terminus the goal, clutter facilitates the breaking of patterns, creative thinking [22], free and innovative ideas [23]. Disorder is needed to create a rupture [24]. However, there is research that associates home organization with stress reduction and higher well-being. So, as long as we are not in a task 
that requires us to break the patterns of our own thinking, the most effective way to achieve our goal is to be organized.

The biggest enemy for organizational skill in today's society is abundance, defined by too many stimuli, material possibilities, and unlimited mobility. Stress, the psychological response to the environment and its demands, is the enemy of the organizational skills. There is a conflict between the essential in life and the non-priority, and the effect is a lack of organizational skills, on the background of stress. When a person has to give quick answers, stress results, and stress leads to a momentary inability to organize.

The competence of organization includes in its internal logic the personal will and the way of action, on a personal level, through the lifestyle and at a professional level, through the work style. Competence is developed in a social context and can be educated at school level through a pedagogy of the organization [25], and in the field of work through a management of the organizational skills, promoted by employers. All these approaches are subordinated to the vision and values of the society to which the individual belongs.

Organizational skill is about personal will and exercise. The management of the organization must aim not only to transmit a set of rules and intellectual disciplines but also the personal development of the individual, because the organization being a transversal competence, any change of behaviour at work must attract changes in personal life, otherwise the individual, manifesting resistance to change, tends to return to the previous most comfortable situation [26].

Approaching the development of organizational competence, which is directly reflected in personal lifestyle and work, can be done through two concepts: minimalism and KonMari technique. These can be addressed both in the school, through the pedagogy of the organization, and at the workplace through organizational management.

Minimalism is a philosophy that can be applied in any area of life and aims to reduce a thing / action / experience to its essential, fundamental parts [27]. Minimalism is defined by "less means more", capitalizing on the potential of any element of our lives, so as to increase the quality of products and services and, most importantly, to bring joy. Minimalism means a cluster wardrobe, with a small number of clothing items that can be combined and recombined, can mean a frugal meal, with few, simple, quality elements. The antonym of minimalism in our society is consumerism, the long run, compulsive shopping, which reflects current needs current needs and not medium and long-term ones. A space organized according to the minimalist philosophy, with few things, airy, does not create stress, is more restful and much easier to organize and maintain.

The KonMari technique is invented by Marie Kondo, an organization act expert from Japan. She is currently the producer of TV shows and the author of four books about organization act [28]. Her exceptional ideas, along with minimalist principles can become two techniques transposed at educational and organizational level, through pedagogy and organization management.

The aim of the paper is to analyse the concept of organizational skill, from a psychological perspective, as a volitional approach or acquired through learning, and from a methodical perspective, as a process developed through the pedagogy of the organization and the management of the organizational skills. In the application part, the level of organization of the work style and lifestyle of a group of students from the Faculty of Engineering from Sibiu was analysed.

The objectives of the study are the following:

- Analysis of the concept of organizational skill, from a psychological and procedural perspective;

- Measuring the level of organization of the work style of a group of students from the Faculty of Engineering; 
- Observing the level of organization of the lifestyle of a group of students from the Faculty of Engineering;

- Comparing the level of work organization and learning with that of personal life.

- Identifying strategies for developing students' organizational competence in the university environment.

\section{Materials and Methods}

The research was attended by a group of 48 students from the Faculty of Engineering in Sibiu, Romania. The group consisted of all students who participated in a seminar about production organization and in which four colleagues proposed two activities to assess the level of organizational skills. The students were in the 4th year of study. $73 \%$ of the students were female and $27 \%$ male. The tests used were administered both on paper and online. The data obtained were analysed using IBM SPSS Statistics v23.

\subsection{Test for evaluating the organization of work style}

The questionnaire analyses 5 key elements of productivity: organizational skills, attitude, delegation, information integration and efficient use of productivity systems [29]. The concept of organization is analysed from the following perspectives:

- Organizing the learning space, in order to facilitate concentration;

- Reducing the search time of the necessary objects;

- Time management;

- Effective learning planning;

- The organization act requires a high degree of awareness;

- Techniques for organizing for things;

- Self-knowledge for organizing activities according to the maximum hourly efficiency [28].

The questionnaire consists of 15 questions, with 5 answers, from never - 1 point to always - 5 points. The minimum score obtained is 15 and the maximum 75 . The final scores are analysed on 3 intervals, interval 1 between 15 and 31, interval 2 between 32 and 53, and interval 3 between 54 and 75 . For interval 1, the organizational skills are at a minimum level, people having too many tasks that they do not prioritize. Scores in range 2 indicate an average level of organizational skills, in which tasks are largely completed, while for range 3 , the level of organizational skills is very good. The scores obtained in the test were calculated and analysed according to the gender of the participants.

\subsection{Evaluating the lifestyle organization}

Observing the organization of the lifestyle was done through an activity in which each student has to analyse the objects in the room where they live and group them into three categories: what I throw away, what I keep and what I leave for later, meaning postpone. Objects that require postponement mean that either the person has not yet decided whether the object is to be thrown away or kept, or has not identify the location for it in the room.

Both questionnaires, for the identification of organizational skills in activity and for the analysis of organizational skills in everyday life, were anonymously.

\section{Results and discussions}




\subsection{Analysis of the test for evaluating the organization of work style}

Following the application of the questionnaire, an average score of 47.16 points was obtained, the average of females being slightly lower than that of males, 46.57 versus 49.25. Figure 1 shows the scores obtained on the analysed intervals. There were no scores on the first interval, which defines the minimum level of organizational skills. $83 \%$ of people enrol in the average level of the organizational skills, and $17 \%$ have a very good level of organizational skills. Among people with an excellent level of organizational skills, $33 \%$ were female and $67 \%$ male.

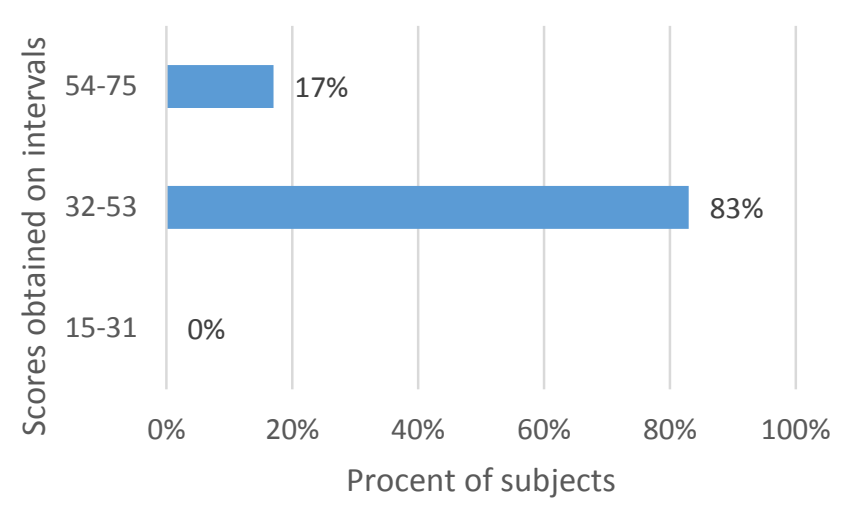

Fig 1. Results obtained on analysed intervals

In conclusion, it is observed that the level of organizational skills of students is medium, and can be improved. A slight difference is observed between females and males, men being slightly more organized than women, according to Figure 6 .

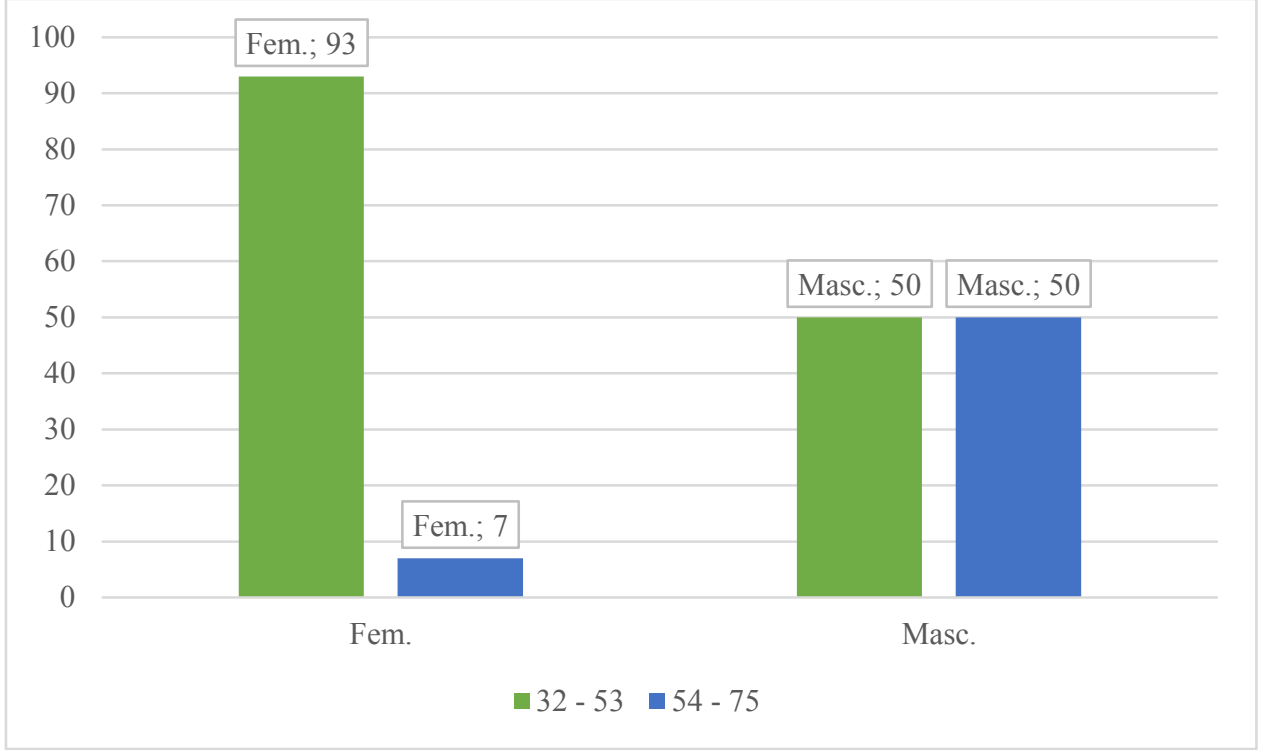

Fig 2. Analysis of results by intervals, depending on gender 


\subsection{Lifestyle organization analysis}

The organization of the students' answers according to the three categories, what I throw away, what I keep and what I leave for later, was done based on the criteria presented in the book Magic of Order, written by the organizing expert Marie Kondo [28]. The answers were grouped into the five categories presented in the book, categories that help organize and order things, plus a sixth category, garbage.

The categories in which the students' answers were grouped are shown in Figure 2.

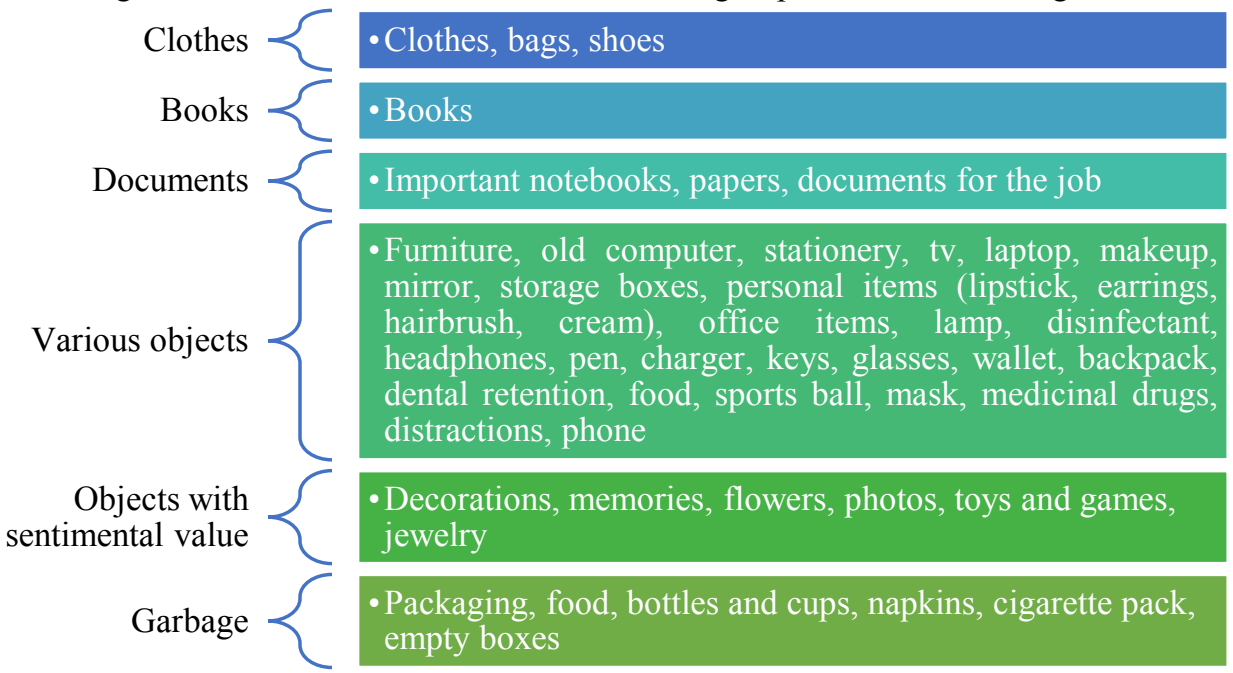

Fig 3. Student answers on grouping categories

A total of 169 objects were listed, grouped by category according to Figure 4 .

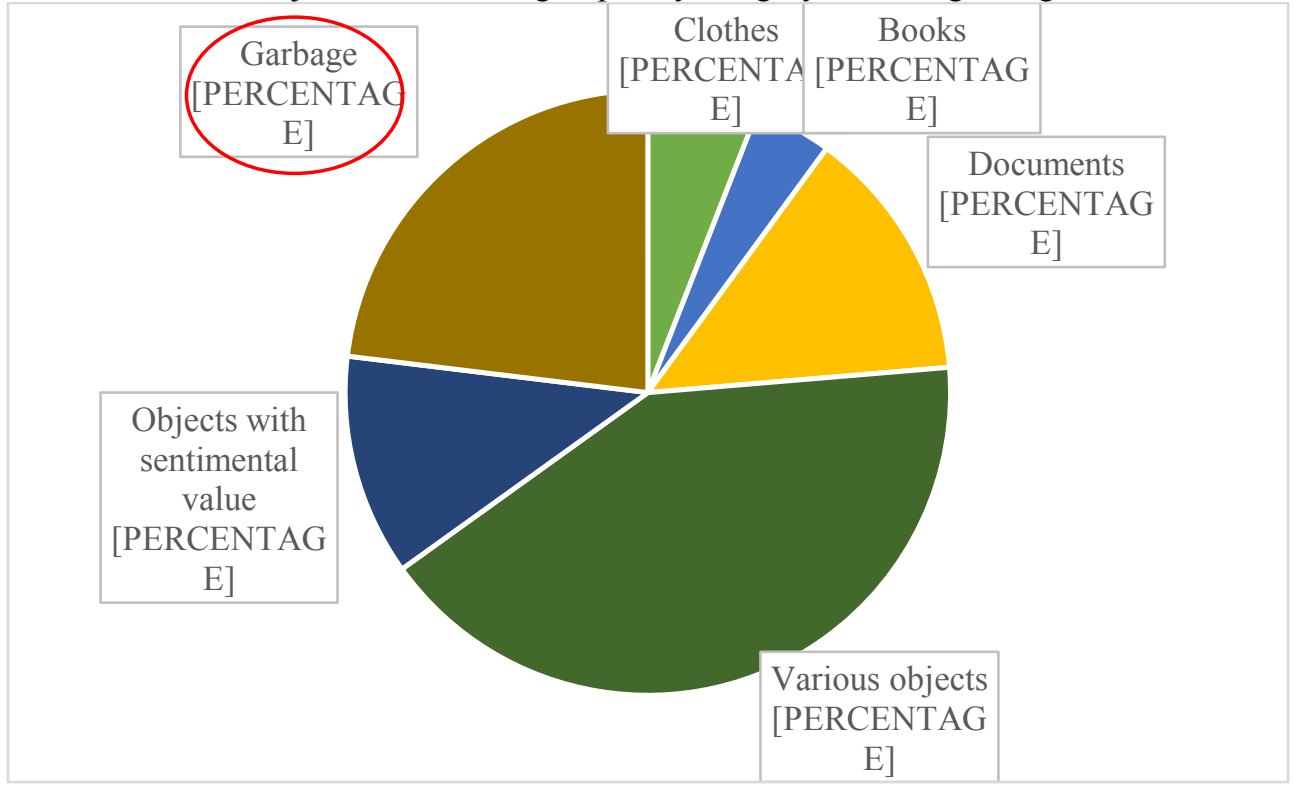

Fig 4. The weight of the categories related to the total number of answers 
It is observed that garbage occupies a very high percentage among the objects in the personal rooms of the students.

Figure 5 shows the percentages in which things were named for the three actions taken: throw, keep and postpone.

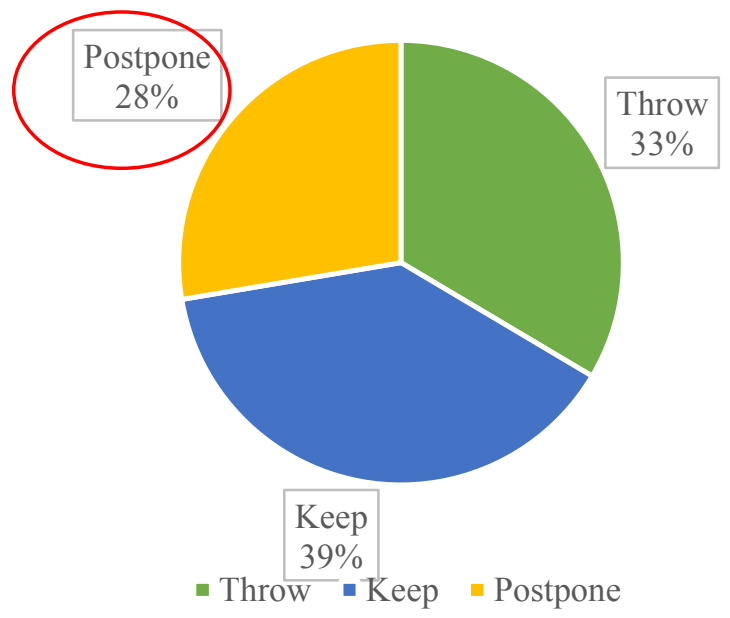

Fig 5. Percentages of things chosen on the three actions made by students

Students tended to name more things to the action of keeping, but the percentage of things thrown away is close to that of postponed.

Figure 6 shows the number of things chosen by students, depending on the type of action taken and the category of objects.

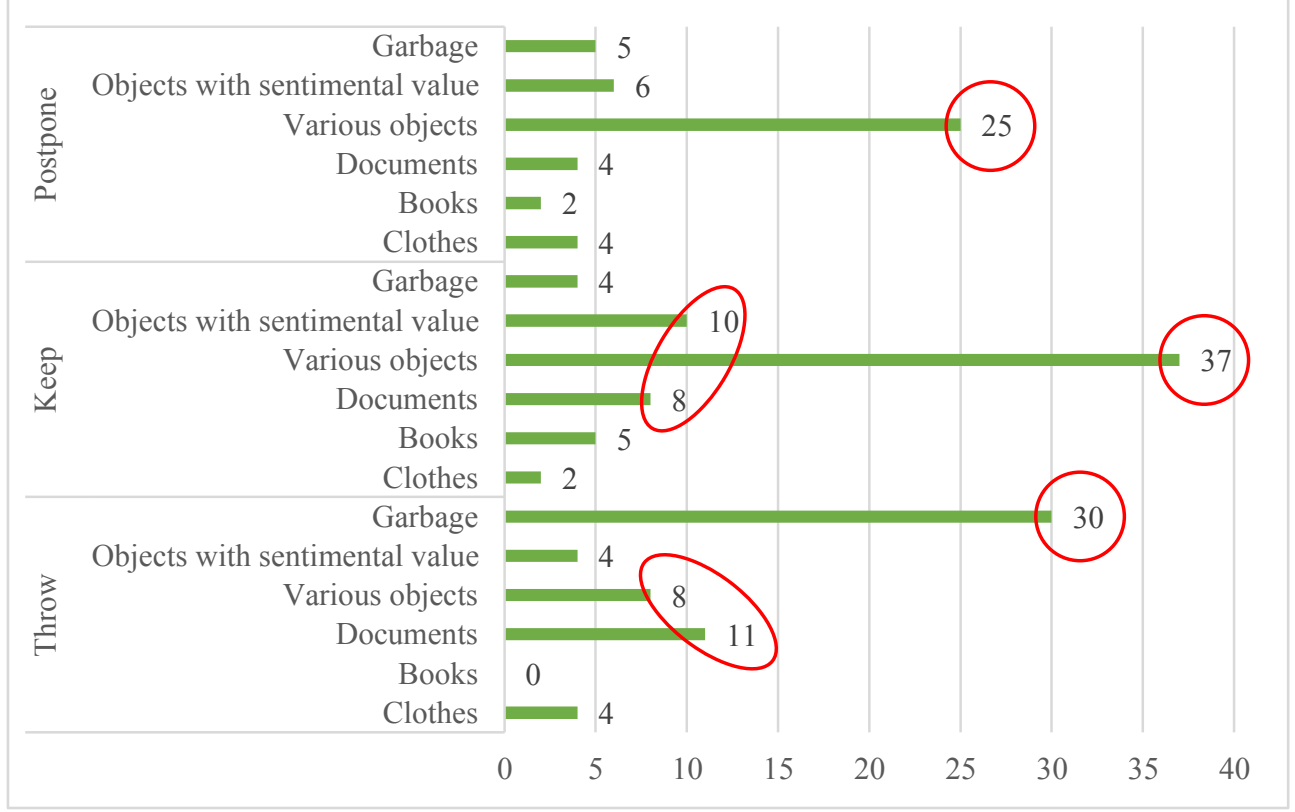

Fig 6. Grouping things by actions and categories 
For the throwing action, the students named 53\% garbage, and neutral objects from emotionally point of view had a share of $33 \%$. Only $7 \%$ of the objects thrown were those with sentimental value.

For the action Keep, the various objects were the most numerous, $56 \%$, followed by those with sentimental value $15 \%$, and documents $12 \%$.

$53 \%$ of the objects left behind are various objects. $13 \%$ of the postponed objects are those with sentimental value.

The analysis of lifestyle organization, on the 6 categories, is done taking into account the gender of the participants, female and male. Of the total subjects, $73 \%$ were female and $27 \%$ male.

Women tend to have more objects than men, women named 6 objects on average, and men named 4.75 , but throw and keep just as many. Men postpone finding a suitable place for an object more than women. Figure 7 shows the average values of the number of options by category, depending on gender.

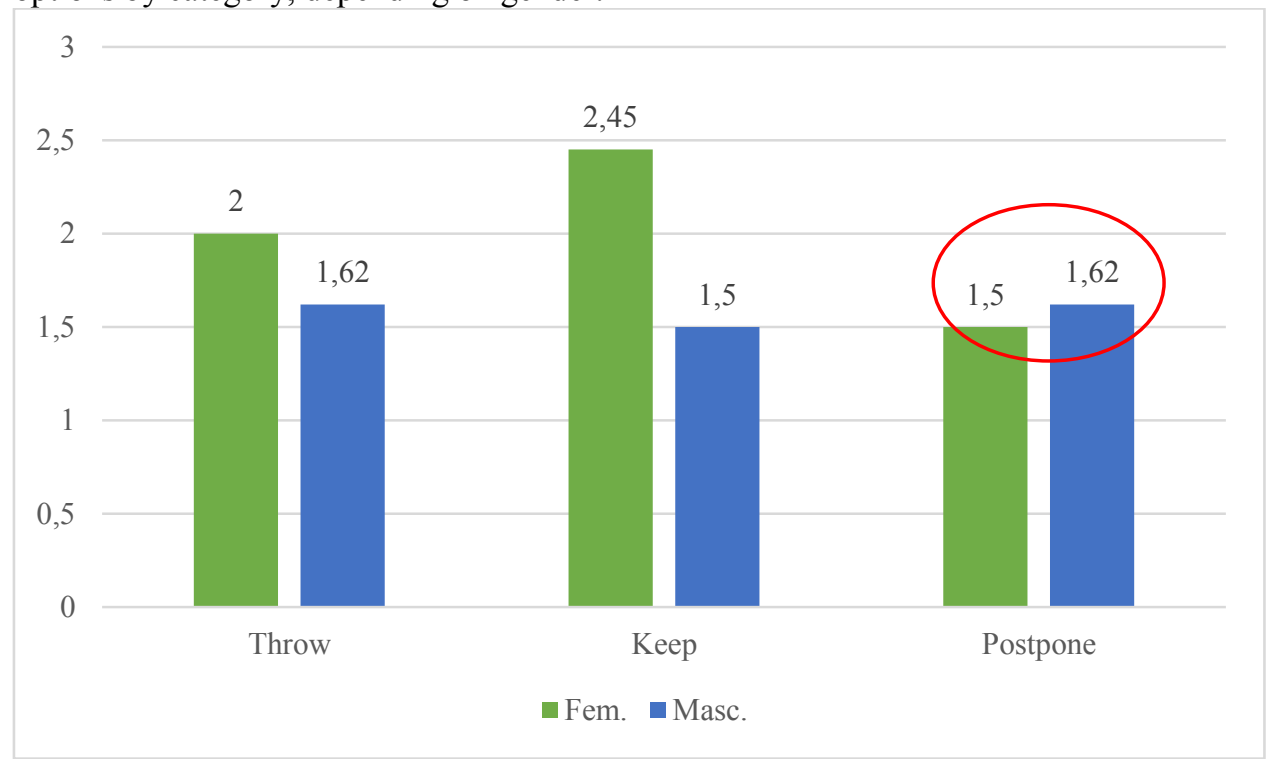

Fig 7. Average number of objects chosen by actions, depending on gender

Women have $29 \%$ more garbage in the room than men. Women tend to have more personal belongings than men (the chi-square coefficient is significant, $0,001<0,005$ ) and invest with $52 \%$ more emotions in things (the chi-square coefficient is significant, $0,001<0,005$ ). Women have $56 \%$ more books, $70 \%$ clothes and miscellaneous items than men. Figure 8 shows in red the areas of objects in which the gender differences are greater than $50 \%$. 


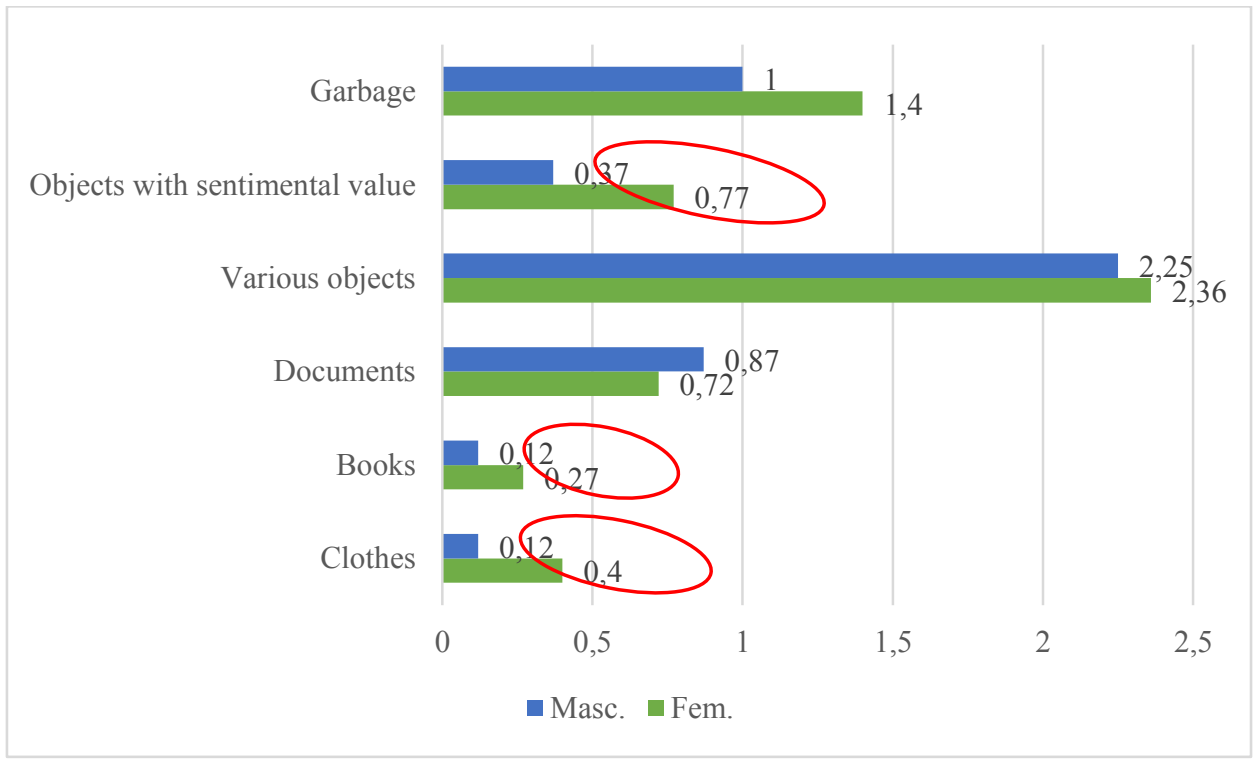

Fig 8. Average types of objects grouped by categories and gender

Women tend to keep objects in the garbage category longer (the chi-square coefficient is significant, $0,001<0,005$ ), or postpone throwing them away, according to Figure 9 . Women quickly decide to keep various items, while men postpone the decision to keep them or find a suitable place for them.

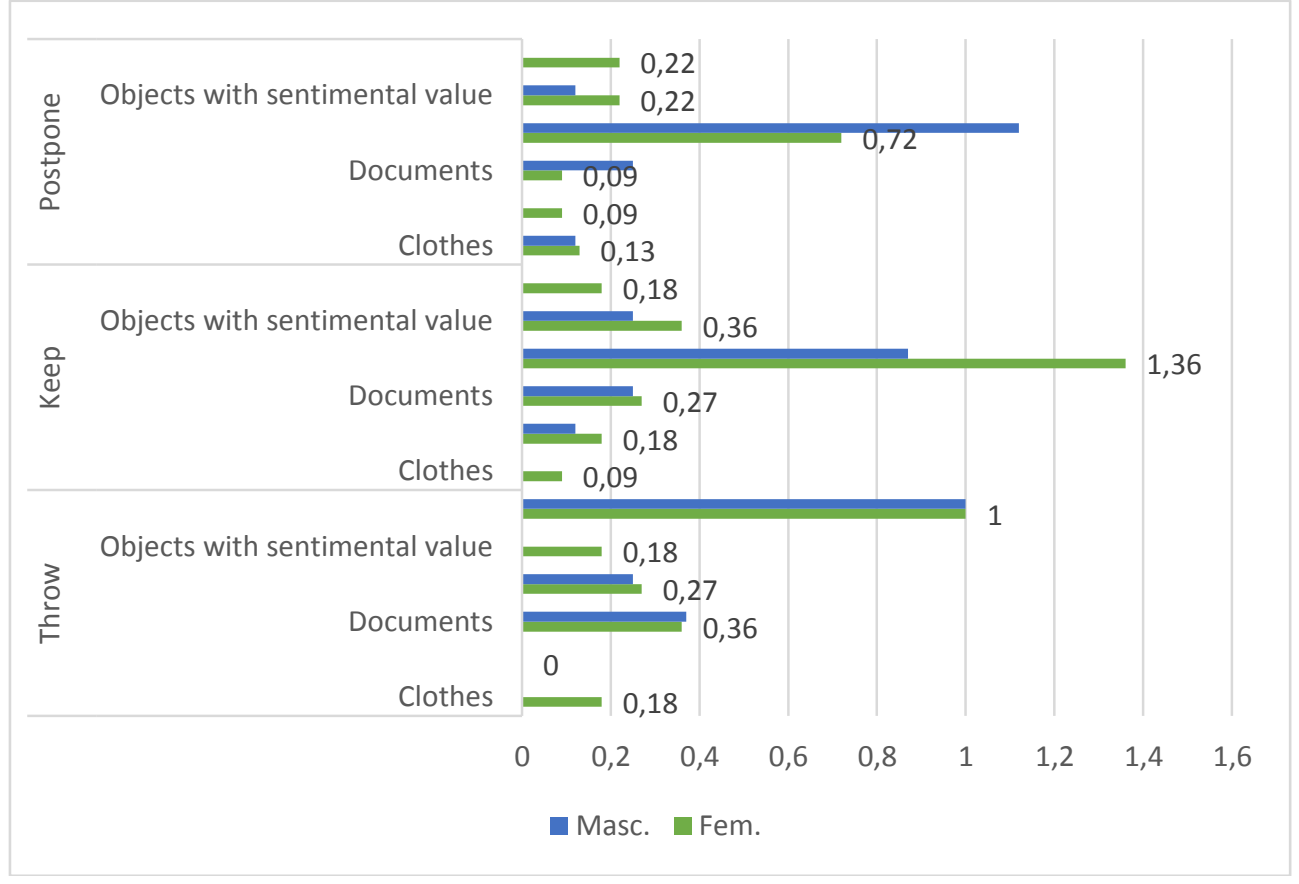

Fig 9. Grouping things by actions, categories and gender 


\subsection{Comparative analysis of work organization with that of lifestyle}

Analysing the results obtained from the two research approaches, it can be stated that there are gender differences in the ability to organize. Men tend to be more organized than women. They have even fewer objects that they keep longer, so their style is simpler, oriented towards minimalism. Women have a higher fluctuation of objects than men.

The results of the test on self-assessment of organizational ability are slightly higher than those of the test of organization. If the majority of people declare themselves to have a good and very good level of organizational skills, apart from objects in their personal space, garbage occupies almost a quarter, which leads to a low level of organizational skills.

A possible explanation for the large amount of garbage in the personal space is the online activity during the pandemic, which tends to transform the personal space into a work space, dining room and any other space necessary for activities that cannot be carried out in a specific place specially designed, such as sports.

The development of organizational competence can be approached from the perspective of private and professional life. During the university studies, time management, planning of the learning process and professional development can be improved, by participating in additional seminars, development of technical projects, and development of internship at companies in the business environment [3-6].

At the university level, a program can be implemented to develop organizational competence, with two coordinates:

1. Organization of the physical environment:

- Introduction and monitoring of rules about the use of classrooms: chairs at tables before leaving the classroom, throwing glasses and bottles in the trash, emptying bins more often, leaving the tables clean after activities.

- Training sessions for students about ways to organize lifestyle and workstyle, in which they can participate in the practice week.

2. Mental organization:

- The last week of didactic activity in each discipline should be allocated for structuring the exam materials.

- A piece of evaluation of the activity carried out at the seminar or laboratory should be schemes and graphics for organizing the course material.

- Providing meditations to students for learning support, which must be attended by all those with grades below 8 .

- Permanent evaluation for the organizational act of personal objects during teaching activities (handbags, backpacks, drinks and food), as a means of increasing mental concentration and reducing stress.

- Avoid multitasking, in the sense of offering a single task to students in a unit of time.

\section{Conclusions}

Considering the study described above, the following conclusions can be drawn:

- Garbage occupies $23 \%$ of the listed objects around the investigated group.

- The group tend to postpone organizing $30 \%$ of its time and actions.

- Objects with sentimental value tend to be kept or the postponement of resolving their situation.

- The analysed group tends to overestimate its organizational capacity.

- Of the total things that define lifestyle, $27 \%$ are out of place and the group tends to postpone solving this problem.

- There are gender differences on the ability of organization, which can change up to $60 \%$ of a person's lifestyle and work. 
- During the pandemic, personal space interferes with the work space in the analysed group, which can lead to the need for additional organizational acts and can generate more garbage.

Organizational competence improves lifestyle and workstyle, acquired either through voluntary self-effort [30] or in a formal setting, reducing stress, developing punctuality, increasing task-solving ability and productivity. Organizational skills help the sustainable use of resources, both intellectual and environmental [31-33], whether we are talking about raw materials [34], objects around us or the rational use of forms of energy. In conclusion, the ability to sustainably organize brings peace and security in personal and professional life, creates a high-performance workstyle and a low-cost lifestyle, which brings joy.

\section{Study implications and limitations}

An identified limitation of the study is the number of participants and the voluntary accidental sampling. A major, impact study on a large number of participants on the current state of students' organizational skills would clearly identify the need and opportunity to introduce training modules in this direction at university level. Another limitation of the study is the type of questionnaire used to evaluate the organization of work style. The test is self-administered, so it increases the subjectivity on the evaluation of organizational skills.

The research can be a primary analysis of the needs and values of work and personal life, which should be extended in further studies to a larger number of participants, in order to constitute a possible direction of approach to learning at university level.

\section{Future research directions}

A possible future direction of research could be the realization of an experimental research in which to introduce strategies to improve the organizational skills of students in all the specific activities carried out at university level. Developing the organizational skills of novice teachers or newcomers to the system can be another useful direction of research.

This work was supported by the Erasmus + Programme, SafeEngine project, contract no 2020-1RO01-KA203-080085. We would like to thank Solomon Anna, Lotrean Cristina Elena, David Patricia and Teșcut Adrian who proposed to the students the subject of the present research.

\section{References}

1. A. Română, Dicționarul explicativ al limbii române (Univers Enciclopedic, București, 2016)

2. M. Christodoulou, E. Szczygieł, Ł. Kłapa, W. Kolarz, Algoritmică şi Programarea. Materiale de pregătire pentru profesori (P.T.E.A. Wszechnica Sp. z o.o., Krosno, 2018)

3. M. Vysotskaya, Time management as a means of self-organization of educational activities of students of a pedagogical university (Dissertation, Master of pedagogical Sciences, KSPU named after Astafyev, Krasnoyarsk, pp 48-57, 2018)

4. Y. Agranovich, A. Amirova, L. Ageyeva, L. Lebedeva, S. Aldibekova, E. Uaidullakyzy, The formation of self-organizational skills of student's academic activity on the basis of 'time management' technology, International Journal of Emerging Technologies in Learning (iJET), 14(22) (2019)

5. B. McKenna, D. Finamore, E. V. Hewitt, L. Watson, L. A. Millam, M. Reinhardt, The Effect of a Multifactor Orientation on Student Performance: Organizational Skills, 
Goal Setting, Orientation to Classroom, and Academic Support. Online Learning, 22(4), 265-276 (2018)

6. N. G. Bravo Rosillo, M. E. Intriago Cedeno, A. N. Rosillo Suarez, Organizational strengthening of the popular and solidarity economic units-textile area \& the technical and organizational skills. Revista San Gregorio, (28), 82-93 (2018)

7. U. Burnik, M. Meža, Open-source impedance measurement instrument development project enhances engineering students' technical and organizational skills. The International journal of engineering education, 33(6), 1751-1762 (2017)

8. S. A. Schramm, T. Hennig, F. Linderkamp, Training problem solving and organizational skills in adolescents with attention-deficit/hyperactivity disorder: A randomized controlled trial. Journal of Cognitive Education and Psychology, 15(3), 391-411 (2016)

9. M. J. Kofler, D. E. Sarver, S. L. Harmon, A. Moltisanti, P. A. Aduen, E. F. Soto, N. Ferretti, Working memory and organizational skills problems in ADHD. Journal of Child Psychology and Psychiatry, 59(1), 57-67 (2018)

10. S.J. Molitor, J.M. Langberg, S.W. Evans, et al. Evaluating the Factor Validity of the Children's Organizational Skills Scale in Youth with ADHD. School Mental Health 9, 143-156 (2017)

11. P. A. LaCount, C. M. Hartung, C. R. Shelton, A. E. Stevens, Efficacy of an Organizational Skills Intervention for College Students with ADHD Symptomatology and Academic Difficulties. Journal of Attention Disorders, 22(4), 356-367. https://doi.org/10.1177/1087054715594423 (2018).

12. G. Durand, I. S. Arbone, M. Wharton, Reduced organizational skills in adults with ADHD are due to deficits in persistence, not in strategies. PeerJ, 8, e9844 (2020)

13. R. M. Kern, P. R. Rasmussen, S. L. Byrd, L. K. Wittschen, Lifestyle, personality, and attention deficit hyperactivity disorder in young adults. The Journal of Individual Psychology, 55, 186-199 (1999)

14. J. B. Meaux, A. Green, L. Broussard, ADHD in the college student: A block in the road. Journal of Psychiatric and Mental Health Nursing, 16, 248-256. doi:10.1111/j.1365- 2850.2008.01349.x (2009)

15. K. A. Schwanz, L. J. Palm, S. A. Brallier, Attention problems and hyperactivity as predictors of college grade point average. Journal of Attention Disorders, 11, 368373. doi:10.1177/1087054707305155 (2007)

16. A. Guiette, P. Matthyssens, K. Vandenbempt, Organizing mindfully for relevant process research on strategic change, Journal of Business \& Industrial Marketing, vol. 29, nr. 7-8, pp. 610-618 (2014)

17. G. Bala, A. Hosek-Momirovic, S. Golubovic, Aberrant behaviour and cognitive ability in preschool children, Psihologija, vol. 40, nr. 4, pp. 509-525 (2007)

18. J. A. Dusek, H. Eichenbaum, The hippocampus and memory for orderly stimulus relations, Proceedings of The National Academy Of Sciences Of The United States Of America, vol. 94, nr. 13, pp. 7109-7114 (1997)

19. T. Vedinaş, Introducere în antropologie (Universitatea "Babeş-Bolyai", Cluj-Napoca, 2006)

20. A. Tattersall, The global spread of community organizing: how 'Alinsky-style' community organizing travelled to Australia and what we learnt? Community Development Journal, vol. 50, nr. 3, pp. 380-396 (2015)

21. G. R. Patterson, Orderly change in a stable world - the antisocial trait as a chimera, Journal of Consulting and Clinical Psychology, vol. 61, nr. 6, pp. 911-919 (1993)

22. L. I. Cioca, R. A. Nerișanu, Enhancing Creativity: Using visual mnemonic devices in the teaching process in order to develop creativity in students, Sustainability, vol. 12, nr. 5 (2020) 
23. A. Serghescu, In camera ta e curat sau dezordine? Ce spune asta despre tine, ziare.com, 16112015 (2015)

24. E. Weiner, Geografia geniului (Niculescu, București, 2017)

25. M. A. Carter, Social rules according to young children, Australasian Journal of Early Childhood, vol. 41, nr. 2, pp. 32-40 (2016)

26. J. Long, P. Gaynor, A. Erwin, Organizational life-style as a predictor of student teaching performance, education, vol. 113, nr. 3, pp. 511-\& (1993)

27. „Wikipedia,” [Interactiv]. Available: https://ro.wikipedia.org/wiki/Minimalism. [Accesat 1503 2021] (2021)

28. M. Kondo, Magia ordinii - Senzaționala metodă japoneză de a-ți elibera și organiza casa (Lifestyle, București, 2015)

29. Marsilian, Admiterea. De la BAC la Buget, Grileadmitere. www.grile-admitere.ro (2020)

30. V. Botnari, L. Laşcu, Competenţa de self-management a activităţii de învăţare la studenţi-prioritate actuală a învăţământului academic, Acta Et Commentationes Sciences of Education, vol. 2, nr. 7, pp. 4-13 (2019)

31. D. Wong, E. Ngai, Economic, organizational, and environmental capabilities for business sustainability competence: Findings from case studies in the fashion business, Journal of Business Research, vol. 126, pp. 440-471 (2021)

32. I. Bratu, Open-source solutions to improve the quality of sustainable forest management, in 9th International Conference On Manufacturing Science And Education (Mse 2019): Trends In New Industrial Revolution (2019)

33. A. Namdari, R. Shakouri, Study of the Mmechanism for Organizing the Environment with the Minimum Physical Eelements (Through the lens of Amos Rapoport Theory: Organization of Environment) (Case study: Qashqai Nomad's Dwelling), Bagh-E Nazar, vol. 15, nr. 67, pp. 5-18 (2019)

34. I. Blada, S. Tanasie, C. Dinu, I. Bratu, Growth, straightness and survival at age 32 in a Pinus strobus $x$ P. wallichiana F-1 hybrid population (Experiment 1), Annals of Forest Research, vol. 56, nr. 2, pp. 269-282 (2013) 